\title{
ANTIHYPERTENSIVE EFFECTS OF $\beta$-BLOCKERS IN HYPERTENSIVE RATS
}

\author{
Keisuke TAKEDA, Hiroshi SAKURAI and Shoichi IMAI \\ Department of Pharmacology, Nïgata University School of Medicine, Niizata, Japan \\ Accepted December 2, 1974
}

Although the anthypertensive activity of propranolol and other $\beta$-blocking agents is clearly documented in man, the mechanism of this action is still not well understood. One of the main reasons for this situation is the difficulty to demonstrate the antihypertensive action of the $\beta$-blocking agents in the commonly used animal models of hypertension. Only two reports have thus far mentioned this effect $(1,2)$. In the present study an attempt was made to reproduce the antihypertensive action of $\beta$-blockers in conscious hypertensive rats by long-term administration of the drugs, and to offer some explanation of the mode of action. As $\beta$-blockers, propranolol and pindolol were chosen, the former, as a representative $\beta$-blocker with a cardioinhibitory effect and the latter, as a $\beta$-blocker with minimal depressant action on the cardiac contractility. Three doses of pindolol were used, namely, 3,10 and $30 \mathrm{mg} / \mathrm{kg}$, while the dose of propranolol was set at $100 \mathrm{mg} / \mathrm{kg}$, a dose which produces an approximately equivalent $\beta$-blocking action to that produced by the maximal dose of pindolol, and which produced an antihypertensive effect in spontaneously hypertensive rats (SHR) after prolonged administration (2). Drugs were given daily by artificial gavage. Three types of animal models of hypertension were used for the experiments, i.e., SHR, and DOCA- and renal-hypertensive rats. Blood pressure of the animals was determined twice a week using the tail plethysmographic method.

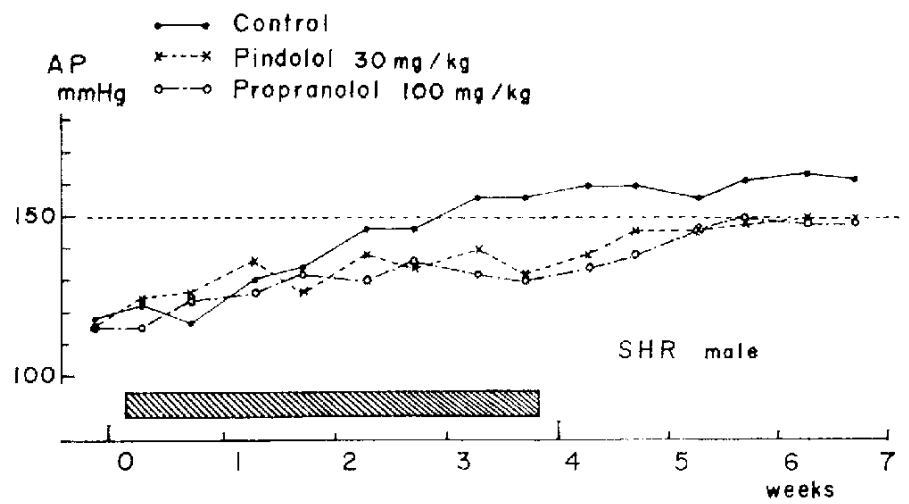

Fio. 1. Antihypertensive effect of $\beta$-blockers in spontaneously hypertensive rats (SHR). Each point represents the mean of 5 animals.

AP : Blood pressure determined by a tail plethysmographic method.

Drugs were given daily by artificial gavage during the period shown by a hatched bar. 
Fig. 1 illustrates the effects of pindolol $(30 \mathrm{mg} / \mathrm{kg}$ per day) and of propranolol (100 mg/kg per day) on the initial stage of hypertension of male SHR's. These rats were purchased from the Nippon Rat Co., Urawa, Japan. They are of $F_{27}$ generation and were maintained on the normal commercial diet (Oriental MF) containing $0.5 \%$ sodium and tap water ad libitmm. Administration of the drugs was initiated at the age of 4 weeks when the average body weight of the animals was 54.7-1.2 g and the average systolic blood pressure was $113.5-1.9 \mathrm{~mm} \mathrm{Hg}$. Thereafter, the systolic blood pressure of the control animal rose steadily, attaining a pressure of higher than $150 \mathrm{~mm} \mathrm{Hg}$ within 3 weeks. Pindolol or propranolol effectively prevented this steady rise of the blood pressure, the difference of blood pressure between the control and the treated animals becoming statistically significant two weeks after starting the administration of the $\beta$-blockers. The blood pressure remained lower as long as the drug administration was continued, but started to rise again when the drug was discontinued. The antihypertensive effect of pindolol was dose-dependent and even the lowest dose ( $3 \mathrm{mg} / \mathrm{kg}$ per day) was effective in preventing the rise of blood pressure. There was no difference between the body weight of the control animals and that of the treated animals during the entire course of the experiments.

Wister-Imamichi rats of either sex, weighing between 180 and 350 g were used to induce the renal and DOCA-hypertension. DOCA (50 $\mathrm{mg} / \mathrm{kg})$ was injected subcutaneously once a week, as $25 \mathrm{mg} / \mathrm{ml}$ suspension in $4 \%$ gum arabic after unilateral nephrectomy (keft kidney). Instead of tap water $1 \% \mathrm{NaCl}$ was given as drinking water. Renal hypertension was produced, by placing a clamp made from silver ribbon around the left renal artery (slit width, $0.2 \mathrm{~mm}$ ), without contralateral nephrectomy. Administration of $\beta$ blockers was started two days after operation in these wo types of experiments. Neither pindolol nor propranolol produced antihypertensive effects.

As Plummer (3) pointed ou in his review on the experimental hypertension in animals, clamping of one kidney while leaving the other untouched leads to an incrcase in renin concentration in the clamped kidney and the blood, suggesting the possible active participation of the renin-angiotensin system in the initiation of the renal hypertension. Braun-Menendez. (4) called attention to the fact that the development of the DOCA-hypertension is intimately connected with an increase in the blood volume. Inability of the two $\beta$-blockers to prevent the development of high blood pressure in these two type of experimental hypertension indicates that the antihypertensive effect of the $\beta$-blockers is not connected either with the renin-angiotensin mechanism or with a reversal of the increase in the blood volume. Since the dose of pindolol equipotent to propranolol as $\beta$-blocker produced an antihypertensive effect of the same intensity as that achieved by the latter, it may be concluded that the antihypertensive action of these two substances is linked to the specific $\beta$-blocking activity, rather than to the non-specific cardioinhibitory action. Okamoto et al. (5) suggested that the initial stage of hypertension in SHR's is intimately related with the hyperactivity of the sympathoadrenal system. Prevention by $\beta$-blockers of the rise of the blood pressure in SHR observed in the present study may be due to the 
blockade of this sympathetic hyperactivity. Whether the blockade occurred in the periphery or within the central nervous system is not clear at present, although the recent paper by Day et al. (6) suggests the CNS as the site of this antagonism. Although some investigators noted the sympathetic hyperactivity in the DOCA-hypertension $(7,8)$, two $\beta$-blockers used in this study were not effective in this type of hypertension. We have at present no explanations for this discrepancy.

Addendum in proof: The antihypertentive effect of propranolol, unlike that of pindolol, was later found to be variable depending upon the batches of SHR's.

\section{REFERENCES}

1) Rora, J., Lambelin, G. and DeSchaepdryver, A.F.: Archs int. Pharmacodyn. Thér. 200, 182 (1972); 2) Folkow, B.: Acta physiol. scand. 84, 8A (1972); 3) Plummer, A.J.: Antihypertensive Agents, Edited by Schlittler, E., Academic Press, New York, London, (1967); 4) BradN-Menendez, E.: Hypertension. Edited by Bell, E.T., A Symposium, University of Minnesota Press, Minneapolis, 1951; 5) Okamoto, K.; Int. Rev. exp. Path. 7, 227 (1969): 6) Day, M.D. and Ronch, A.G.: Nature, New Biol. 242, 30 (1973); 7) De Champlain, J., KraKOFF, L.R. ANd AXELrod, J.: Circulation Res. 24-25, Suppl. I, 75 (1969); 8) NakamLra, K., Nakamura, K. and Mizogami, S.: Japan. J. Pharmacol. 23, Suppl., 24 (1973) 